\title{
$\mathrm{DMT}$ 화차의 곡선부 주행특성에 관한 연구
}

\section{A Study on Curve Running Characteristic of DMT Freight}

\author{
이 승 일†.엄 범 규*.이 희 성**.이 영 엽****.김 용 원****
}

Seung Il Lee, Beom Gyu Eom, Hi Sung Lee, Young Yeob Lee and Yong Won Kim

(2010년 1월 21일 접수 ; 2010년 3월 19일 심사완료)

Key Words : DMT Freight(Dual Mode Trailer 화차), Running Characteristic(주행특성), Railway Vehicle(철도차 량), Curve(곡선부)

\begin{abstract}
An interest is increased of environment and energy so, importance on railroad high energy efficiency is magnified. And after Gyeong-bu High speed rail is completed, share rate freight transportation of railroad is expected to be gradually increased due to expand investment for railroad and operate mainly freight transportation on convention line. Therefore a research on DMT freight cars is necessary under like this situation. In paper, we developed analysis model for DMT freight car and DMT freight was analyzed numerically using VI-Rail in each condition of railway having different curve and carried out vibration analysis on curving using developed analysis model. And we carried out test on driving stability follow changing curve radius then measure against UIC code 518.
\end{abstract}

\section{1. 서 론}

\section{1 연구의 배경 및 목적}

국내외 물동량이 빠른 추세로 증가하면서 국내 물류산업도 지속적으로 발전해 가고 있다. 정부에서 도 물류의 중요성을 감안하여 물류산업을 국가전략 산업으로 설정하고 국가 물류 인프라 구축과 물류 산업 발전에 예산과 역량을 집중하고 있다. 물류산 업의 기반이 되는 국내외 화물은 급성장 추세를 보 이고 있다. 이러한 성장세는 동북아 지역의 경제협 력 가속화에 따른 인적-물적 자원의 역내(域內) 교 류 증가와 맞물려 앞으로도 상당기간 지속될 것으 로 보인다. 물류시장의 확대에도 불구하고 국내 물

† 교신저자; 정회원, 한국철도대학 철도차량기계과

E-mail : leeyil@hanmail.net

Tel : (070)8855-1653, Fax : (031)462-2944

* 서울산업대학교 철도전문대학원 철도차량시스템 공학과정

** 서울산업대학교 철도전문대학원 철도차량시스템학과

**** 한국철도공사 연구원

****국토해양부 교통정책실 자동차정책과
류산업은 여전히 상당한 구조적 문제점을 지니고 있다. 선진국에 비해 생산성도 낮을 뿐 아니라 물류 업체들의 전문성도 상대적으로 낮은 수준이다. 또한 도로수송의 의존비가 지나치게 높아 운송비도 상대 적으로 높을 수밖에 없는 구조를 가지고 있다(1). 이 와같은 물류산업의 낙후성은 산업의 경쟁력에도 큰 영향을 미치고 있다. 1991년 이후 다품종, 소량 생 산체계로의 산업구조의 변화로 인해 도로 화물운송 시장은 급속하게 발전하였으나, 철도 화물 운송량은 1991년 14,494백만ton $\times \mathrm{km}$ 를 정점으로 지속적으로 감소하는 추세이며 최근 8 년간('01 ' 08 년)은 평균 10,766 백만ton $\times \mathrm{km}$ 수준을 수송하고 있다. 1990년 대 이후 철도수송량은 지속적으로 감소하여 왔으나, 소규모 화물역 정비, 실적이 저조한 화물열차 운행 수 폐지 등 화물열차의 거점간 대량수송체계 구축 을 위한 각종 정책 추진으로 최근에는 열차 당 평 균 수송거리 및 평균수송량이 지속적으로 증가 추 세에 있다. 향후 환경 및 에너지에 대한 국제적인 관심증대로 친환경적이고 에너지 효율이 높은 철도 
Table 1 DMT transport system present condition of world

\begin{tabular}{|c|c|c|c|}
\hline \multicolumn{2}{|r|}{ Dividing } & $\begin{array}{c}\text { Operation/ } \\
\text { development nation }\end{array}$ & Feature \\
\hline \multirow[b]{2}{*}{$\begin{array}{l}\text { Piggy } \\
\text { back }\end{array}$} & $\begin{array}{c}\text { US type } \\
\text { (TOFC method) }\end{array}$ & US & -Santa Fe railway development TOFC freight use \\
\hline & $\begin{array}{c}\text { European type } \\
\text { (kangaroo method) }\end{array}$ & $\begin{array}{l}\text { France, Germany, } \\
\text { Italian etc } \\
\text { International } \\
\text { transportation }\end{array}$ & $\begin{array}{l}\text {-The freight car use which lowers the center department } \\
\text { of normal } \\
\text {-The vertical as a matter of cargo work in compliance } \\
\text { with an upper unloading equipment }\end{array}$ \\
\hline \multicolumn{2}{|r|}{ Bimodal } & $\begin{array}{l}\text { US, Australia, New } \\
\text { zealand, England, } \\
\text { Germany, France, } \\
\text { Spain, Greece }\end{array}$ & $\begin{array}{l}\text {-The freight car without back and the railroad direct } \\
\text { transportation } \\
\text {-In transportation method fringe land timely disturbance } \\
\text { excess } \\
\text {-The terminal expense and trailer pulling do not occur } \\
\text { almost, }\end{array}$ \\
\hline \multirow{3}{*}{$\begin{array}{l}\text { Freight } \\
\text { rotation } \\
\text { style }\end{array}$} & Modalohr & $\begin{array}{c}\text { France } \\
\text { (development), } \\
\text { Luxembourg, Italian }\end{array}$ & $\begin{array}{l}\text {-France Lohr groups development commercial business } \\
\text {-one day } 5 \text { reciprocation train business operating }\end{array}$ \\
\hline & Cargo speed & $\begin{array}{c}\text { England } \\
\text { (development) }\end{array}$ & $\begin{array}{l}\text {-England Cargo Speed international company development } \\
\text {-Is not operated in incomplete condition of technique }\end{array}$ \\
\hline & Flexi waggon & $\begin{array}{c}\text { Sweden } \\
\text { (development) }\end{array}$ & $\begin{array}{l}\text {-Sweden Flexiwaggon AB company development } \\
\text {-The terminal equipment is not a necessity. } \\
\text {-Freight car structure is complicated and is unstable and } \\
\text { until currently does not become commercial business. }\end{array}$ \\
\hline \multirow{2}{*}{$\begin{array}{l}\text { Parallel } \\
\text { transfer } \\
\text { style }\end{array}$} & Cargo beamer & $\begin{array}{c}\text { Germany } \\
\text { (development/design) }\end{array}$ & $\begin{array}{l}\text {-2004 Cargo Beamer AG company design } \\
\text {-With } 2010 \text { commercial business aim while developing }\end{array}$ \\
\hline & Cargo domino & Swiss & $\begin{array}{l}\text {-SBB Cargo development } \\
\text {-From } 2002 \text { commercial business }\end{array}$ \\
\hline
\end{tabular}

의 중요성 부각으로 철도에 대한 관심이 증대될 전 망이고, 온실가스 배출 억제를 위한 교토의정서 발 효('05.2), 국제유가 급등 등으로 철도의 역할 확대 가 필요하다. 또한 경부고속철도 전 구간 완공 후 기존선의 화물위주 운영 및 철도에 대한 투자확대 로 인해 철도의 화물수송 분담률이 점진적 증대가 예상된다(2). 그러므로 이러한 철도의 화물수송 분담 률 증대에 따른 DMT(dual mode trailer) 화차에 대 한 연구가 절실히 요구된다.

이 연구에서는 DMT 화차의 해석모델을 개발하 였고, 개발된 해석모델을 이용하여 곡선부 주행에 따른 DMT화차의 주행 진동해석을 수행하였다. 또 한 곡선반경 변화에 따른 주행안전성 평가를 수행 하고 이를 UIC Code 518 제한치와 비교하였다.

\section{DMT 화차 기술개발 현황}

\section{1 국외 DMT 화차 개발현황}

선진국 철도물류수송시스템으로 개발되거나 현재 적용되고 있는 시스템으로는 피기백(piggyback), 바이 모달(bimodal), 화차 회전형, 수평 이적재형으로 나눌
수 있다. 화차 회전형은 다시 모달로(modalohr), 카고 스피드(cargo speed), 플랙시웨건(flexiwaggon)으로 분류할 수 있고, 수평 이적재형은 카고도미노(cargo domino)와 카고스피드로 분류된다. 주로 피기백 시 스템, 바이모달 방식은 운영된 바가 있으나, 현재 그 효율성에 있어서는 그다지 좋은 평을 얻지 못하 는 실정이다. 유럽에서는 화차회전형 및 수평 이적 재형 수송 시스템 등을 개발 중이며, 모달로 시스템 은 현재 상용화되고 있으며, 그 외 회전 및 수평 이 적재 시스템은 시운전을 앞두고 있다. 수평 이적재 형 수송시스템으로는 카고 비머, 카고 도미노가 주 로 개발되고 있다. Table 1은 세계의 DMT 수송시 스템 현황을 나타내고 있다 ${ }^{(1)}$. Table 2는 화차 회전 식과 수평 이적재식을 비교하여 나타내었다 ${ }^{(2)}$.

\section{2 국내 DMT 화차 개발현황}

$\mathrm{DMT}$ 차량개발은 DMT 수송시스템의 성패를 좌 우하는 핵심기술로서 컨테이너 화차의 일부 개조로 적용 가능한 수송시스템으로 컨테이너 $20 \mathrm{ft}, 40 \mathrm{ft}$ 각 각 적재가 가능하고 상면의 이송장치를 이용하여 보다 빠르고 안전한 방식으로 이적재 및 안전성을 
Table 2 Comparison of freight car rotation style and horizontal transfer style

\begin{tabular}{|c|c|c|}
\hline $\begin{array}{c}\text { Method } \\
\text { Item }\end{array}$ & Freight rotation style & Parallel transfer style \\
\hline Joint bogie necessity & $\bigcirc$ & $\mathrm{X}$ \\
\hline The present freight car application right or wrong & $\mathrm{X}$ & $\triangle($ part reorganization $)$ \\
\hline Existing trailer chassis application right or wrong & $\bigcirc$ & $\mathrm{X}$ \\
\hline Actual example of use & O(france modalohr) & $\bigcirc($ swiss cargo domino $)$ \\
\hline Work time (30 stocks work time) & 25 minute & 54 minute (6YT case) \\
\hline Existing rail traffic system application right or wrong & $\mathrm{X}$ & O \\
\hline $\mathrm{CY}$ system necessary areas of container & $\begin{array}{l}\text { The necessary area } \\
\text { with a load is big }\end{array}$ & $\begin{array}{l}\text { The necessary area } \\
\text { with a many item load is small }\end{array}$ \\
\hline Disturbance facility & $\begin{array}{c}\text { Hydraulic drive system and } \\
\text { hydraulic feed mechanism } \\
\text { whole aspect terminal }\end{array}$ & $\begin{array}{l}\text { Tractor and hydraulic feed } \\
\text { mechanism }\end{array}$ \\
\hline Concurrent job characteristic & O & $\bigcirc$ (BLOCK unit) \\
\hline Whether to contact in axle load (below 22ton) & $\triangle$ & O \\
\hline Vehicle limits whether to contact & $\bigcirc$ & $\bigcirc$ \\
\hline Only container transportation right or wrong & $\mathrm{X}$ & O \\
\hline Under aerial building work right or wrong & $\bigcirc$ & $\bigcirc$ \\
\hline
\end{tabular}

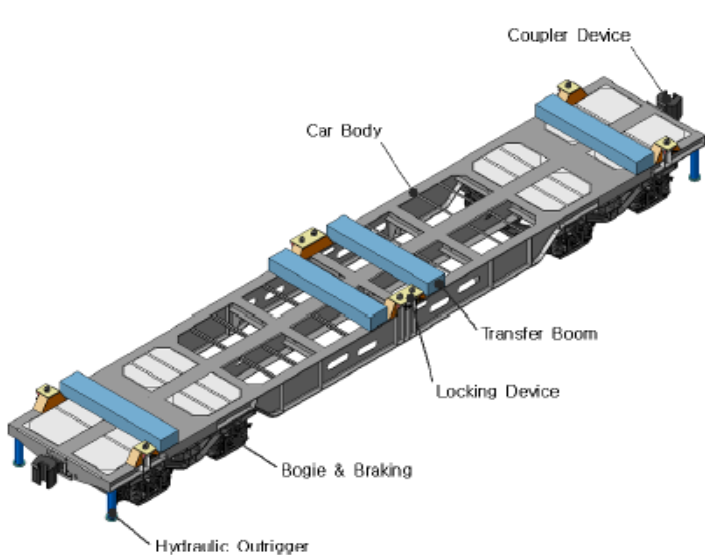

Fig. 1 Composition of korean DMT vehicle

확보하는 방안 설계가 이루어져야 한다. 화차 회전형 시스템은 컨테이너(1AA) 및 high cubic(1AAA) 컨테 이너 적재 시 차량 한계를 만족하며 뛰어난 화물 이 적재를 위한 시스템으로 수평이적재형을 개발 중에 있으며 차량의 구성은 차체(car-body), 대차 및 제동 (bogie \& braking), 연결기 장치(coupler device), 유압 아우트리거(hydraulic outrigger), 록킹장치(locking device), 이송바(transfer boom)등 크게 7가지로 구성 되어 있다. Fig. 1은 개발 중인 DMT 차량의 구성을 나타내고 있다.

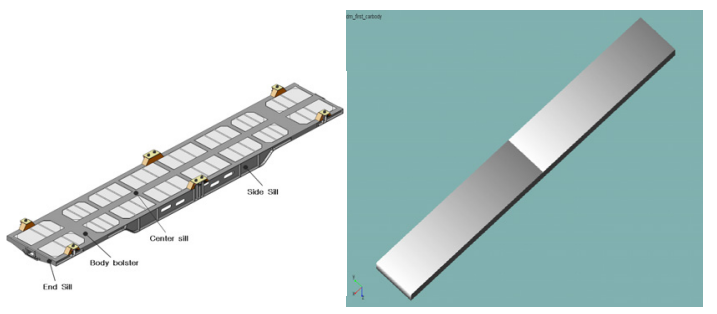

(a) Car-body

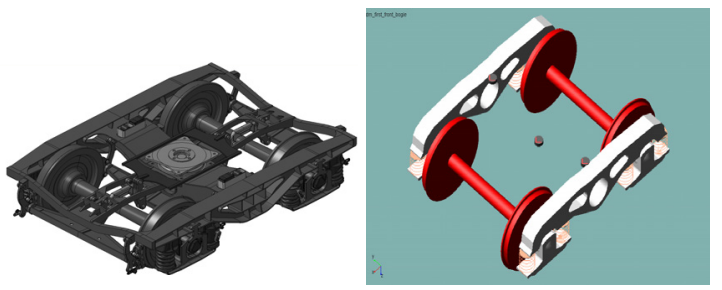

(b) Bogie

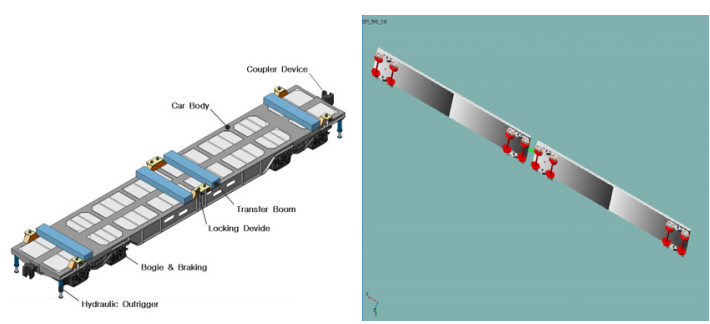

(c) Full assembly

Fig. 2 DMT car model 


\section{3. 해석모델}

\section{1 차량모델}

VI-rail를 이용한 DMT 화차에 대한 해석모델은 차체, 전방대차, 후방대차 세 가지 부분으로 나눌 수 있다. Fig. 2와 같이 차체, 전대차, 후대차를 하 나의 템플릿(template)으로 각각 모델링하고, 서브시 스템(subsystem)을 생성하고, 이들을 이용하여 최종

Table 3 Properties of DMT freight car

\begin{tabular}{|c|c|c|c|}
\hline Dividing & Design element & Value & Unit \\
\hline \multirow{4}{*}{ Carbody } & Mass & 73,000 & $\mathrm{kgf}$ \\
\hline & Roll moment of inertia & 47,500 & $\mathrm{~kg} \cdot \mathrm{m}^{2}$ \\
\hline & Pitch moment of inertia & 510,000 & $\mathrm{~kg} \cdot \mathrm{m}^{2}$ \\
\hline & Yaw moment of inertia & 500,500 & $\mathrm{~kg} \cdot \mathrm{m}^{2}$ \\
\hline \multirow{4}{*}{ Bogie } & Mass & 2,220 & $\mathrm{kgf}$ \\
\hline & Roll moment of inertia & 1,975 & $\mathrm{~kg} \cdot \mathrm{m}^{2}$ \\
\hline & Pitch moment of inertia & 1,560 & $\mathrm{~kg} \cdot \mathrm{m}^{2}$ \\
\hline & Yaw moment of inertia & 2,850 & $\mathrm{~kg} \cdot \mathrm{m}^{2}$ \\
\hline \multirow{4}{*}{ Wheelset } & Mass & 1,300 & $\mathrm{kgf}$ \\
\hline & $\begin{array}{l}\text { Roll, yaw moment of } \\
\text { inertia }\end{array}$ & 699 & $\mathrm{~kg} \cdot \mathrm{m}^{2}$ \\
\hline & Pitch moment of inertia & 100 & $\mathrm{~kg} \cdot \mathrm{m}^{2}$ \\
\hline & Wheel radius & 0.42 & $\mathrm{~m}$ \\
\hline \multirow[b]{2}{*}{ Dimension } & Wheel base & 1.8 & $\mathrm{~m}$ \\
\hline & $\begin{array}{l}\text { Distance of bogie and } \\
\text { bogie between }\end{array}$ & 15.7 & $\mathrm{~m}$ \\
\hline \multirow{3}{*}{ 1'nd spring } & Longitude stiffness & 560,000 & $\mathrm{Ns} / \mathrm{m}$ \\
\hline & Lateral stiffness & 560,000 & $\mathrm{Ns} / \mathrm{m}$ \\
\hline & Vertical stiffness & 400,000 & $\mathrm{Ns} / \mathrm{m}$ \\
\hline
\end{tabular}
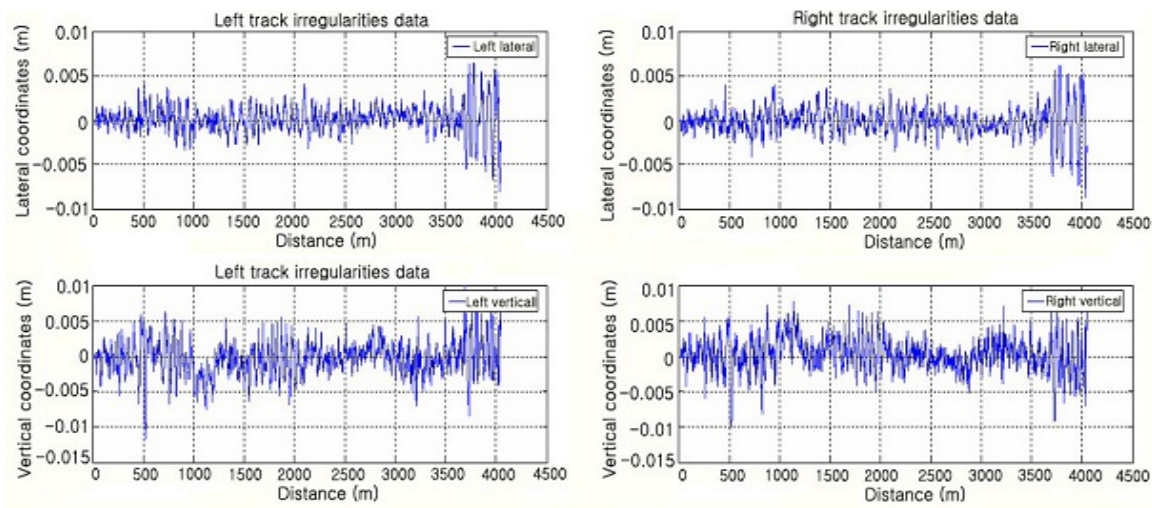

Fig. 3 Irregularity track model

$376 /$ 한국소음진동공학회논문집/제 20 권 제 4 호, 2010년

\section{1 평가인자 계산법}

UIC code 518은 국제적인 운행허가 목적으로 안 전, 궤도피로, 주행거동의 관점과 관련된 동역학적 거동의 관점에서 철도차량(기존 차량, 신기술 차량 과 특수 차량)에 대한 승인절차로서의 노선 주행시 험 및 분석방법을 다루고 있다. 이 규정은 국제적인 허가에 대한 최소 필요조건으로 운행되는 지역에서 만날 수 있는 특정한 심각한 운행조건을 포함하지 는 않는다. 측정하거나 계산된 입력값에서 탈선계 수, 수직하중, 차체 가속도의 평가인자들을 계산하 기 위하여 해당 규정에서 정하는 바에 따라 Fig. 4 와 같이 신호처리와 통계처리를 하였다 ${ }^{(6)}$. 모델은 Y25 대차에 적용되고 있는 차륜답면 구배 가 $1 / 20$ 과 UIC 60 레일을 해석에 사용하였다 ${ }^{(4,5)}$.

\section{4. 해석결과}

\section{2 선로와 차륜/레일모델}

선로모델은 Fig. 3 과 같이 좌우·상하 불규칙궤도 차는 스프링과 댐퍼, 부쉬(bush), 범프 스톱(bump stop) 등 많은 요소를 고려하였다. 연결 시 연결 좌 표를 지정하고, 이를 기준으로 모델을 생성한다.

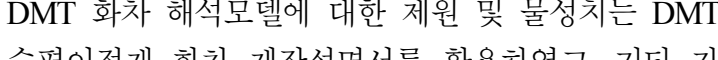
료는 Y25형 대차의 사양을 활용하였다. Table 3은 DMT 화차의 주요제원을 나타내고 있다 ${ }^{(3)}$.

적으로 조립체를 생성한다. 차체의 모델링은 형상 


\section{2 곡선부 주행 진동해석}

개발된 DMT 화차의 해석모델을 이용하여 곡선 부 통과 시 곡선반경에 따른 주행특성 해석을 수행 하였다. 곡선부 주행에 따른 차량진동 특성 검토를 위해 현재 기존선 선로에 다수로 부설된 곡선반경 $\mathrm{R} 400, \mathrm{R} 800$ 을 곡선부 선로모델을 사용하였고, 곡선 부 통과속도는 VI-rail내의 cruise control를 이용하 여 곡선구간에 따라 통과 제한속도를 조절하여 주 행특성을 해석하였다 ${ }^{(4)}$. Table 4는 해석 시 사용된 선로, 곡선 통과속도, 캔트 및 완화곡선 길이를 나 타내고 있다. Table 4를 기준으로 곡선반경(R400, $\mathrm{R} 800)$ 에 따른 실제캔트에서의 주행특성 해석을 수 행하였다.

철도차량 주행 중 가장 큰 가진원은 차륜과 레일 의 접촉에 의해서 발생하고, 이 진동원에 의해 진동 은 차륜 $\rightarrow$ 대차 $\rightarrow$ 차체까지 전달된다. Fig. 5 와 Fig. 6 은 곡선반경 R400 및 R800을 통과하는 DMT 차량 의 차륜, 대차 및 차체 전후 $(\mathrm{x})$, 좌우 $(\mathrm{y})$, 상하 $(\mathrm{z})$ 진 동가속도의 RMS값을 나타내고 있다. Fig. 5와 Fig. 6에서와 같이 상하(z) 및 좌우(y)진동가속도에 대한 제한치를 만족함을 알 수 있다. 진동가속도 RMS값 의 크기는 윤축, 대차, 차체 순으로 나타났다. 이는 1 차, 2 차 현가장치에 의해 진동이 감쇄되고 특히

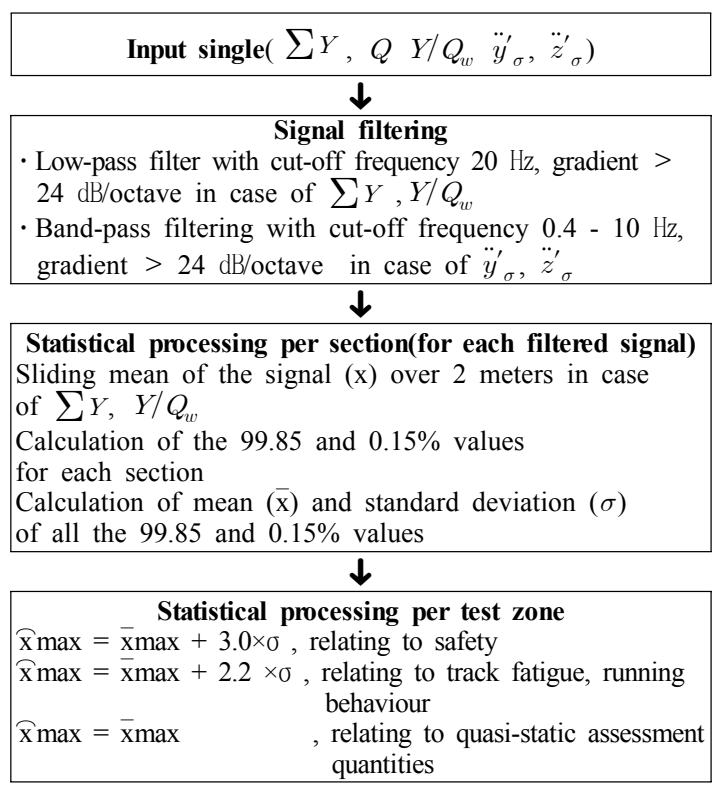

Fig. 4 procedure of signal and statistical processing for calculating assessment quantities 상하(z)진동성분이 크게 감쇄됨을 알 수 있다.

곡선반경에 따른 진동특성을 검토해보면, R400에 서는 좌우(y)진동성분이, R800에서는 상하진동성분 이 다른 방향진동성분보다 크게 나타났다. 이는 급 곡선부에서 원심력에 의해 좌우(y)진동가속도성분이

Table 4 Railway line and section by passing limiting speed condition

\begin{tabular}{c|c|c}
\hline \hline Item & R400 & R800 \\
\hline $\begin{array}{c}\text { Straight line section passing limits } \\
\text { speed }(\mathrm{km} / \mathrm{h})\end{array}$ & \multicolumn{2}{|c}{120} \\
\hline $\begin{array}{c}\text { Curve section passing limits speed } \\
(\mathrm{km} / \mathrm{h})\end{array}$ & 90 & 120 \\
\hline Actual cant $(\mathrm{mm})$ & \multicolumn{2}{|c}{160} \\
\hline $\begin{array}{c}\text { The transition curve length in } \\
\text { compliance with an actual cant }(\mathrm{m})\end{array}$ & \multicolumn{2}{|c}{208} \\
\hline
\end{tabular}

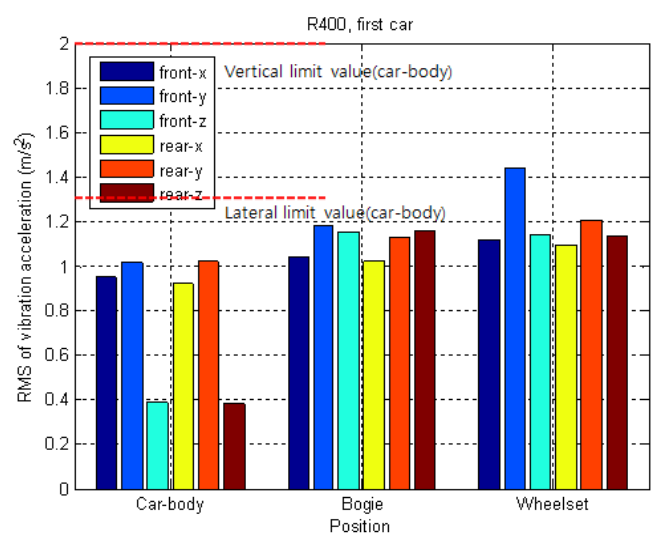

(a) First car

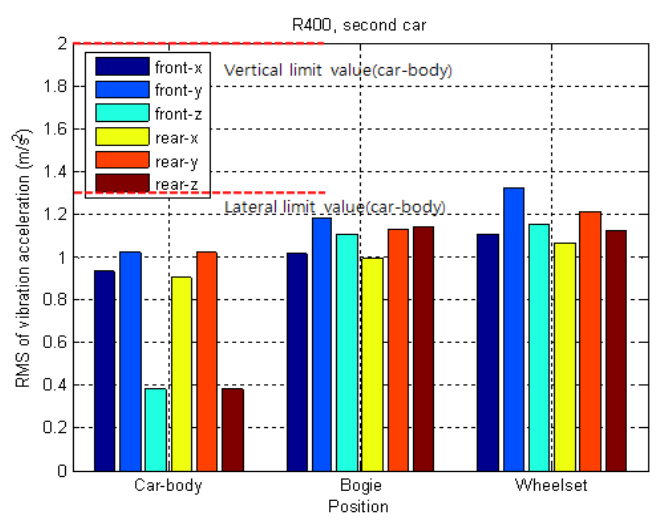

(b) Second car

Fig. 5 RMS of vibration acceleration on curve passing(R400) 


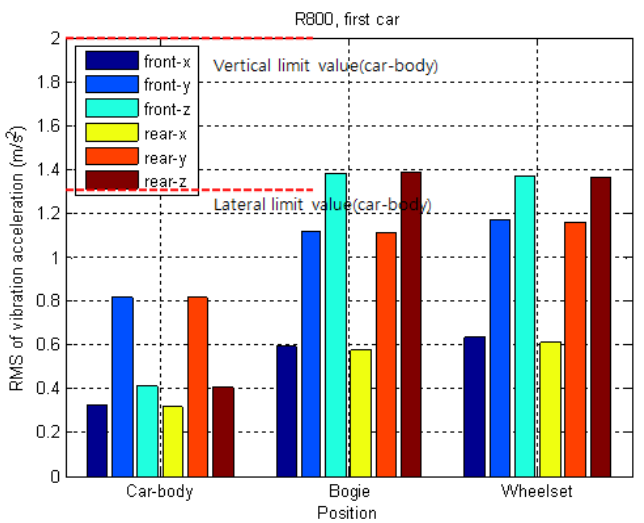

(a) First car

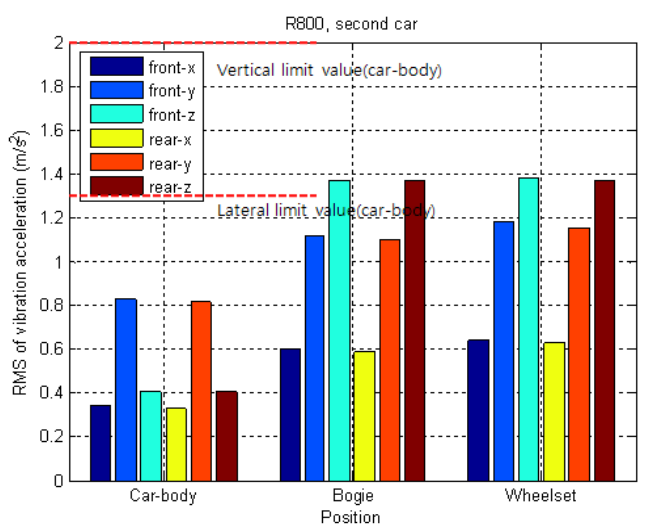

(b) Second car

Fig. 6 RMS of vibration acceleration on curve passing(R800)

크게 나타나고 큰 곡선부에서는 상하진동가속도성 분이 크게 나타남을 알 수 있다.

\section{3 주행안전성 해석}

차량은 직선선로보다는 곡선선로를 주행할 때가 원심력, 횡압 및 윤중감소에 의해 불안전한 주행을 함으로 곡선반경 R400, R800에 따른 탈선계수, 횡압 력, 수직력으로 주행안전성을 검토하였다. Fig. 7은 곡선반경 R400을 제한 속도 $90 \mathrm{~km} / \mathrm{h}$ 로 통과하는 DMT 화차의 탈선계수, 횡압력, 수직력 및 마모지수 를 나타내고 있다. Fig. 7에서와 같이 주행안전성 요 인에 대해서 제한치를 만족함을 알 수 있다. 탈선계 수의 경우, 모든 차량에서 전대차 전차륜이 후대차 후차륜이 약간 크게 나타났다. 이는 차륜답면 구배에 의한 복원력의 영향으로 발생하는 윤축의 요잉 (yawing)현상으로 사료된다. 또한 차륜마모지수는 횡

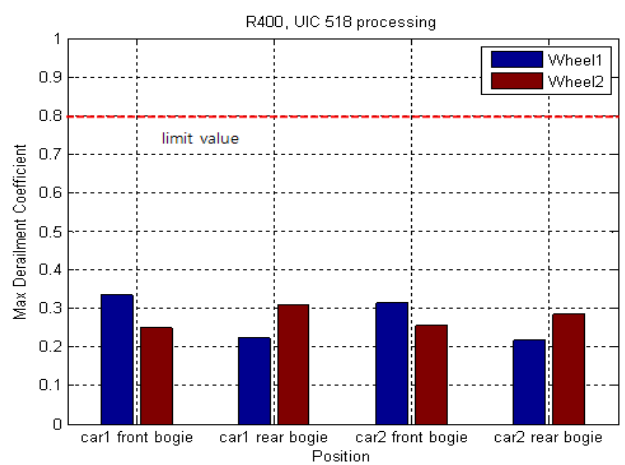

(a) Derailment coefficient

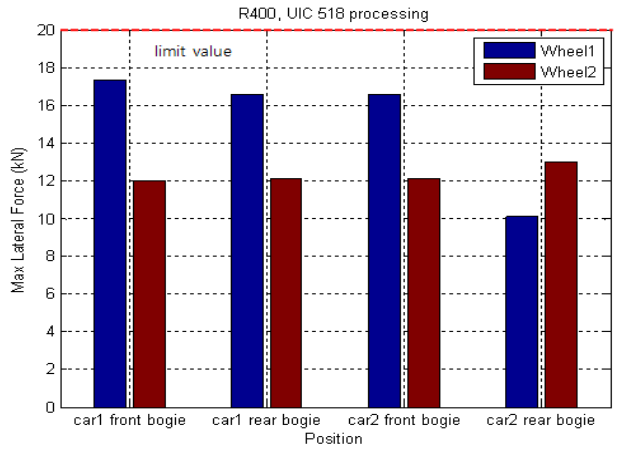

(b) Lateral force

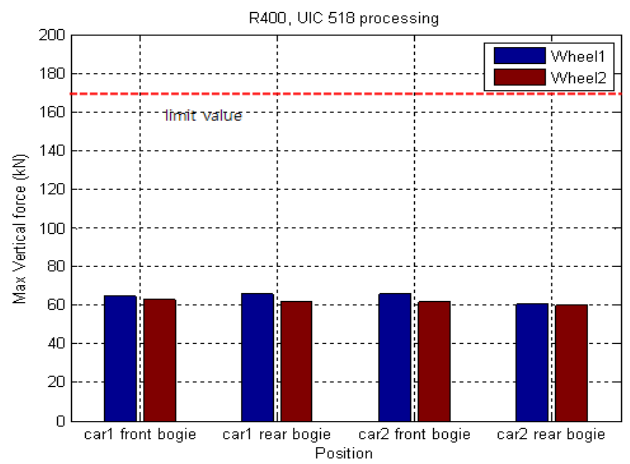

(c) Vertical force

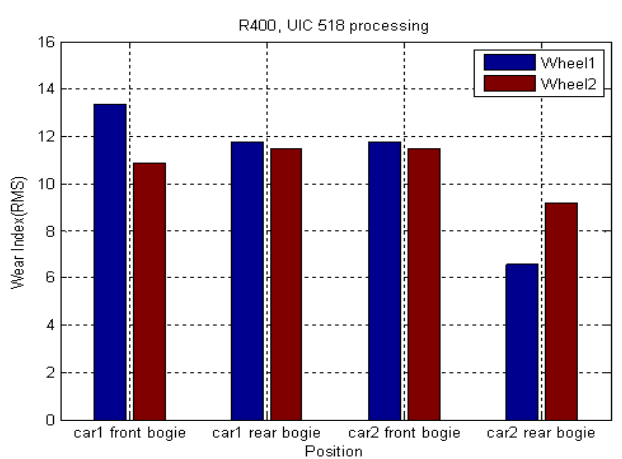

(d) Wear index

Fig. 7 Running safety factor on curve passing(R400) 


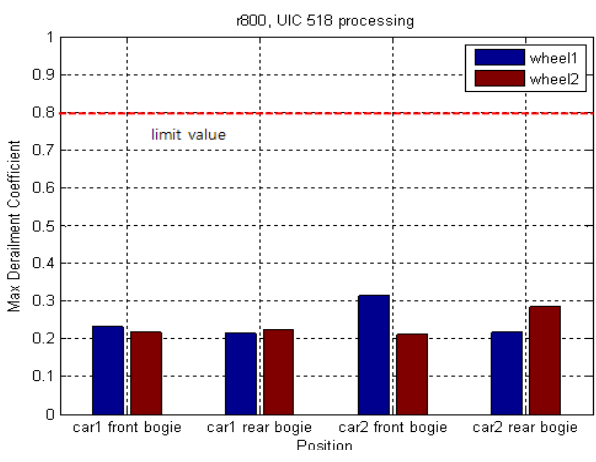

(a) Derailment coefficient

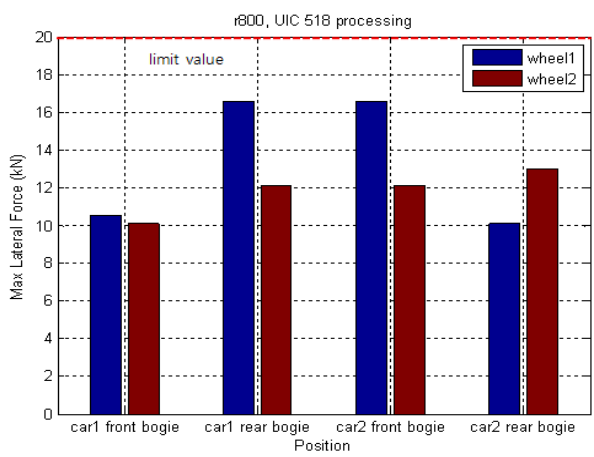

(b) Lateral force

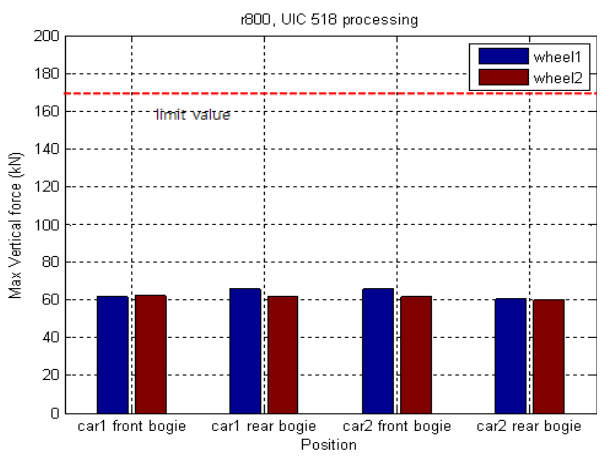

(c) Vertical force

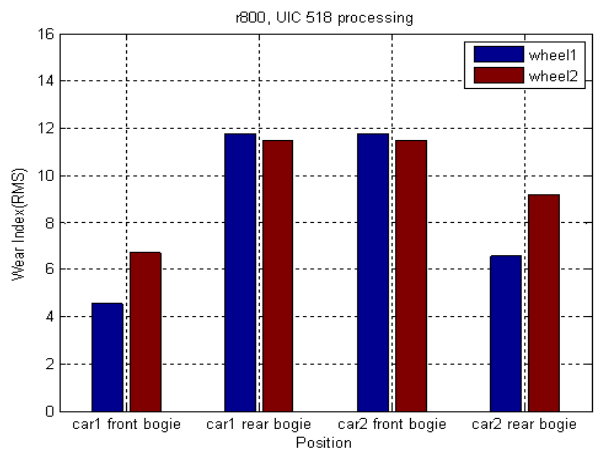

(d) Wear index

Fig. 8 Running safety factor on curve passing(R800)
압력에 의해 영향을 받는 것을 알 수 있다.

Fig. 8은 곡선반경 R800을 제한 속도 $120 \mathrm{~km} / \mathrm{h}$ 로 통과하는 DMT 화차의 탈선계수, 횡압력, 수직력 및 마모지수를 나타내고 있다. Fig. 8에서와 같이 주 행안전성 요인에 대해서 제한치를 만족함을 알 수 있다. 또한 곡선반경 R400보다 모든 요인에서 작게 나타났다. 이는 곡선반경 요인이 주행안전성 평가에 중요한 요인임을 재차 확인할 수 있었다.

\section{5. 결 론}

현재 개발 중인 DMT 화차 해석모델을 이용하여 다물체 동역학 해석도구인 VI-Rail로 해석을 수행하 였다. 선로모델은 곡선반경 R400, R800을 사용하였고, 실제 곡선부 통과제한속도를 부여하기 위해 cruise control로 곡선부 주행해석을 수행하였다.

- 곡선부 주행 진동해석결과, 곡선반경 R400 및 $\mathrm{R} 800$ 을 통과하는 $\mathrm{DMT}$ 화차의 차체 좌우, 상하진 동가속도는 제한치를 만족하였다.

- 주행안전성 해석결과, 곡선반경 R400 및 R800 에서 탈선계수, 횡압력, 수직력 등의 주행안전성 요 인에 대해서 제한치를 만족하였다. 또한 곡선반경 요인이 주행안전성 평가에 중요한 요인임을 재차 확인할 수 있었다.

- 그러나 DMT 화차모델은 실제 개발 중인 DMT 화차에 장착된 수평이송장치, 록킹장치, 아웃트리거, 연결기 등의 요소를 고려하지 않은 제한적 상태에 서 해석을 수행하였으므로 정량적인 평가에서 약간 의 차이가 있을 수 있으므로 이에 대한 상세한 연 구가 필요하다.

\section{참 고 문 헌}

(1) Kim, J. M. and Yin, T. M., 2008, "Study of DMT Localization \& Business Operation System Development," 2008 Symposium Autumn of the Korean Society for Railway, pp. 2075 2089

(2) Kim, J. M. and Lee, Y. S., 2009, "A Study on DMT Transport System for Rail Logistics," 2009 Symposium Spring of the Korean Society for Railway, pp. 1691 1707.

(3) Molatefi, H., Hecht, M. and Kadivar, M. H., 
2006, "Critical Speed and Limit Cycles in the Empty Y-25-freight Wagon,” Proc. Instn Mech. Engrs, Part F: J. Rail and Rapid Transit, Vol.220(F4), pp. 347 359.

(4) Vi grade, 2008, “ADAMS/Rail 2005 R2. 11.0 Documentation."

(5) Park, K. S., Lee, S. I. and Lee, H. S., 2007,

"A Safety Assessment and Vibration Characteristics of Railway Vehicle Passing Curves," Transactions of the Korean Society for Noise and Vibration Engineering, Vol. 17, No. 10, pp. 993 1001.

(6) UIC CODE 518, 2005, "Testing and Approval of Railway Vehicle form the Point of View of Their Dynamic Behaviour-safety-track fatigue-ride Quality," UIC. 3rd ed. 